International Journal of Management

Science and Business Administration

Volume 1, Issue 3, February 2015, Pages

$64-70$

\title{
The Impact of Social Networks on Maximizing the Competitive Value of Micro, Small, and Medium Enterprises
}

\author{
Khaldoun Al-Mommani, Ahmed Al-Afifi, Mohammad Abdullah Mahfuz \\ School of Management, Wuhan University of Technology, Wuhan, China \\ Zhongnan University of Economic and Law, Wuhan, China \\ Corresponding author (e-mail): khldoon.momani@yahoo.com
}

\begin{abstract}
The purpose of this paper is to study the effect of social media and social networks on maximizing and increasing the competitive value of micro, small, and medium enterprises (MSMEs). We review social media, social networks, and marketing literature that demonstrate the importance of social media and social networks in maximizing MSMEs competitive value through exploring the company-customer relationship, and the advantages and disadvantages that social media utilization brings. The findings suggest that micro, small and medium sized enterprises can reap benefits from executing an effective social media marketing strategy. These benefits encompass reducing overall marketing costs, improved customer service through social media, and achieving a competitive advantage. On the other hand, social networks have drawbacks that may affect MSMEs performance and decrease market share, such as time consumption and lack of feedback control. Therefore, MSMEs need to rethink about customer relationship management through building a conceptual and operational framework that provides both structure and flexibility. The study makes a contribution to the theoretical development through focusing on a neglected area of MSMEs research as well as a contribution to the relevance of social media in improving the competitive value of MSMEs.
\end{abstract}

Key words: Social media, Social networks, MSMEs, Competitive value

\section{Introduction}

Social media has changed the way companies are shaping their marketing strategy and communicating with customers. Nowadays firms are able to target specific customers delivering messages that address customers' interest and needs, thus making the overall promotion more effective. Understanding social media and virtual communities is highly 
The Impact of Social Networks on Maximizing the Competitive Value of Micro, Small, and Medium Enterprises

necessary to manage current changes in the business environment. Numerous opportunities created by social media lead community and businesses to create content more efficiently and allow faster communication across global markets (Kalpic and Bernus 2006). Formation and usage of strong social media and social networks can increase the competitiveness of firms and maximize the number of their customers by letting them reach new customers without spending much money (Garrigos et al. 2011). The recent advent of internet and development in information technology, telecommunications and multimedia resulted in a higher number of knowledge and information intensive organizations (Garrigos 2010). Partnerships between firms and other social media agents are helping to create and strengthen the competitive advantages of firms, especially for micro, small, medium enterprises (MSMEs). For instance, more than a billion active Facebook and Twitter users have sent messages, with numbers of messages exceeding 20 billion, illustrating how fast social media has been adopted by consumers and to which extent it influences their life (Chan 2011; Baird and Parasnis 2011). Chu and Meulemans (2008) pointed out that the utilization and dependency on social networks will only increase in the next few years, consequently making social networks invaluable.

Social media is a cost-effective and easy-to-use platform for communication and exchange of information. Social networks enable marketers to develop strategies and to be more targeted and customized. It is also a way for companies to promote their brands, products and services (Kaplan and Haenlein 2010). However, many MSMEs do not understand the impact and the prospects of using social media, and continue to rely on traditional media to communicate with their audience (Vij and James 2014). Following traditional theories of business practice may result in a steady growth of companies (Adizes 1979, Churchill and Lewis 1983, Greiner 1972, Hanks et al 1993), but they may have difficulties addressing the market challenges of the rapidly changing business environment. When it comes to marketing products and convincing customers traditional media has become ineffective (Keller 2009). Thus, businesses should proactively utilize social media, promoting their products and services as it may help them to enhance their brands' competitive position in the market. Therefore, in order to understand customers' needs and reach the largest number of customers firms will need to understand the ways to exploit social media and social networks. In this paper we explore the benefits that micro, small and medium enterprises reap by utilizing social media. By answering the question "Do MSMEs benefit from social media and use it to maximize their competitive market value?" we provide sufficient evidence to justify the adoption of social media tools by organizations. This is done by, firstly, explaining the concept of social media. Next, a brief literature review is conducted illustrating the relationship between social media and organizations' competitive value. Additionally, implications for the practice are presented followed by the conclusion.

\section{Understanding social media}

Kaplan and Haenlein (2010) define social media as "a group of Internet-based applications built on the ideological and technological foundations of the Web that allow the creation and exchange of user-generated content". Social media platforms can be used for communication, 
The Impact of Social Networks on Maximizing the Competitive Value of Micro, Small, and Medium Enterprises

collaboration, education and entertainment. Harris and Ray (2009) pointed out that there are many different types of social media. The categories of social media can be divided into 15 types: social networking (e.g. Facebook, Linkedln, Orkut, etc.), publishing (e.g. Wikipedia and SlideShare), photo, audio and video sharing (e.g. Flickr, YouTube and Vimeo), microblogging (e.g. Twitter, Tumblr, Plurk, etc.), live casting, virtual worlds (such as Second Life), gaming, productivity applications (such as BitTorrent or Google Docs), aggregators (e.g. Digg, Reddit, Yelp, etc.), RSS, search, mobile, and interpersonal. There are various reasons for the use of social networks. According to Ridings and Geffen (2004), people may use it to search for information, social support, friendship and entertainment. Similarly, Wellman and Gulia (1999) stated that people use social networks for information, social/emotional support, a sense of belonging and encouragement, and companionship. Experimental studies by Raacke and BondsRaacke (2008) in the United States, and Yoon and Zhou (2011) in China found that the search for information is the most important reason for social networking. Furthermore, social networks have become crucial not only as means of communication and socialization with friends but also as a platform for sharing information and knowledge. The content is most commonly shared through social networks between individuals, consequently enabling their learning process and adoption of new skills. In fact, the digital gap between the "haves" and "have-nots" is not about access to the Internet but about understanding how to participate effectively in a social networking community (Harris and Ray 2009). People who have skills, time and confidence to navigate and manage the chaos on the Internet can develop and grow their businesses through accessing new opportunities and finding new audiences for their work. Similarly social networks are used by organizations for marketing, and other communication purposes, consequently making them smarter and more efficient.

\section{The importance of social networks for small}

\section{businesses}

Social network is a strategic tool for marketing, monitoring and analyzing the behavior of users (Uhrig et al. 2010). There is a consensus on the importance of the establishment of effective social networks for achieving business success (Wilson and Stokes 2004, Hanna and Walsh 2008). The adoption of social media has resulted in generation of business benefits encompassing improvements of staff quality, internal communications, and community development procedure (Reese, Hopkins 2009). Internet and social networks allow companies to gain access to resources that might otherwise not be available to them. They also help companies increase credibility, expand supplier and customer base, create funding opportunities, encourage innovation, and develop strategic partnerships (Witt 2004).

Business owners rarely have all skills and expertise that are required to develop the company. Many authors like Neergaard et al. (2005) have shown that networks contribute to the effectiveness of marketing in entrepreneurship for the following reasons: "communication is 
The Impact of Social Networks on Maximizing the Competitive Value of Micro, Small, and Medium Enterprises

major aim for MSME owner; using internet network is the best "fit" for this purpose; Therefore, business owners utilize social networks to find skilled people, as well as in the process of managing human resources. With internet and social networks use, geographical location became less important in the recruitment process. A more liberal global labor market and a higher participation rate of the international workforce in foreign countries is partially a result of efforts exerted by "human resource" social networks like "Linkedln" and "Xing". Moreover, the network provides a low cost option for products or service marketing when available resources are limited. Significantly reducing marketing costs result in many advantages for the MSMEs, whereas creating mechanisms, such as blogs, forums and social networks that firms use to communicate with individuals raise their private business profiles (Harris et al 2008). Dennis (2000) pointed out that social networks help collect information, prevent the monopoly and collusion in setting prices. There are also specific types of behaviors characteristic to online communication that may have positive implications for business practice. For instance, Tetan and Allen (2005) found out that people are more likely to be honest when communicating via Internet than in face-to-face communication. This is mainly because there is a written contract and written record of the conversation on the internet, which is considered as evidence of intent, whereas face-to-face discussions can be easily forgotten and do not leave any trace. However, some MSMEs still prefer personal contact.

Marketing in MSMEs differs from marketing in larger firms (Carson et al 1995). Marketing in MSMEs is considered to be easier and more efficient. The traditional strengths of MSMEs include the ability to serve special market and build strong relationships with customers (Collinson and Shaw 2001). However, internet, because of lower transaction costs, helps MSMEs to enter those markets that are dominated by big regional, national and international firms. By choosing not to rely on internet and not to implement online marketing operations MSMEs are exposing themselves to a risk of losing their market shares (Herbig and Hill 1997). Given the numerous benefits that utilization of internet and social media may bring to micro, small and medium enterprises, it is evident that they should channel their marketing efforts toward social media.

\section{Benefits and drawbacks of social media: implications for the practice}

There are many advantages and benefits that MSMEs attain from implementation of an effective social media-marketing plan. First, the overall marketing costs are reduced. The ability to tweet a message or post content on Facebook is more cost effective than running a paid ad. Additionally, there is a chance of offering better customer service through social media. Customers using one of the common platforms like Facebook or Twitter can easily communicate directly with firms and firms can quickly answer them publicly so other customers have access to the provided information as well. MSMEs can achieve a competitive advantage by utilizing social media. Social media can boost their visibility, allow them to provide better 
The Impact of Social Networks on Maximizing the Competitive Value of Micro, Small, and Medium Enterprises

customer service, connect with new business partners, and validate their professional status standing while providing consumers with the value they want.

Pan et al. (2014) pointed out that social media marketing benefits MSMEs in at least two major aspects: cost-efficient communication with customers and capitalization of conversations among customers through word-of-mouth. First, social media provides a cost-effective way to enhance communication with customers, whereas social media marketing helps companies to educate audiences about their services, identify key influencers among customers and respond to them in a timely manner with less cost than traditional communication tools. Secondly, social media marketing capitalizes on word of mouth. Social media enables public customer-tocustomer conversations, and this is one of the most powerful and effective marketing tools available. A number of studies have indicated that the most important source of new customers for small firms is recommendations from existing customers In addition to its advantages, social networks have several disadvantages that may affect MSMEs performance and decrease their market share (Sparrowe et al. 2001). Social networking is time intensive. MSMEs need to focus on establishing long-term relationships that can result in more sales. They have to be responsible to monitor each network, respond to comments, answer questions and post product information which customer deems valuable. Businesses without a service to manage these social networks will find it difficult to compete. The lack of feedback control is one of the biggest disadvantages of social networks (Tolsdorf 1976). It is hard for MSMEs to prevent negative post responses, unhappy customers or industry competitors who are able to post disparaging or offensive pictures, posts or videos. Therefore, social networks must be managed efficiently to immediately respond and neutralize harmful posts, which takes more time. Most social networks are free to join and operate but without paid advertising by the firm, it may not target their customer base; local businesses often end up with followers who are not local. Therefore, firms should collect information from customers regarding their interests and motivations for repeating business. Some of other disadvantages are related to privacy as well as security. However, advantages of social networks highly overweight disadvantages.

\section{Conclusion}

In our paper we demonstrated the importance of social media and social networks in maximizing MSMEs competitive value. The research showed that social networks are used to search for information, social support, friendship and entertainment (Leung and Lee 2005), and it is not just for the use of individuals, but also for marketing, policy, and academic purpose. There are many benefits that micro, small and medium sized firms can achieve with implementation of an effective social media-marketing plan, such as reducing overall marketing costs, offering better customer service through social media and attaining a competitive advantage, Conversely, social networks have many disadvantages that may affect MSMEs performance and decrease their market share such as time consumption and lack of feedback control. Thus far, our research suggested that social media could be a vital pathway for MSMEs to communicate with the communities they serve and to engage new potential customers. MSMEs need to think about customer relationship management from new aspects by building a conceptual and operational framework that provides both structure and flexibility. Further 
The Impact of Social Networks on Maximizing the Competitive Value of Micro, Small, and Medium Enterprises

research is necessary to assess the effectiveness of social media marketing efforts. Future studies could also look into barriers regarding the adoption of social media.

\section{References}

- Adizes, I., Organizational passages: diagnosing and treating life cycle problems in organizations, Organizational Dynamics, 1979, Vol. 8 No.1, pp.3-24.

- Baird, C., and Parasnis, G., From social media to Social CRM: reinventing the customer relationship, Strategy \& Leadership, 2011, Vol. 39, Iss: 6, pp.27 - 34

- Carson, D., Cromie, S., McGowan, P., and Hill, J., Marketing and Entrepreneurship in SMEs: An Innovative Approach, 1995, Prentice-Hall, Harlow.

- Chan, C., Using online advertising to increase the impact of a library Facebook page, Library Management, 2011, Vol. 32 No. 4/5, pp. 361-70.

- Chu, M. and Meulemans, Y., The problems and potential of Myspace and Facebook usage in academic libraries, Internet Reference Services Quarterly, 2008, Vol. 13 No. 1.

- Churchill, N., Lewis, V., The five stages of small business growth, Harvard Business Review, 1983, Vol. 61 No.3.

- Collinson, E., and Shaw, E., Entrepreneurial marketing - a historical perspective, Management Decision, 2001, Vol. 39 No.9, pp.761-6.

- Dennis, C., Networking for marketing advantage, Management Decision, 2000, Vol.38 No.4.

- Garrigos, F., Gil, I., Narangajavana, Y., The impact of social networks in the competitiveness of the firms, in Beckford, A.M., Larsen, J.P. (Eds),Competitiveness: Psychology, Production, Impact and Global Trends, Nova Science Publishers, Hauppauge, NY, 2011.

- Greiner, L., Evolution and revolution as organizations grow, Harvard Business Review, Vol. 50, 1972, No.4, pp.37-46.

- Hanna, V., and Walsh, K., Interfirm cooperation among small manufacturing firms, International Small Business Journal, 2008, Vol. 26 No.3.

- Harris, L., Ray, A., The revenge of the gifted amateur: be afraid, be very afraid, Journal of Small Business and Enterprise Development, 2009, Vol. 16 No.4.

- Harris, L., Ray, A., and Grewal, S., Out on the pull: how small firms are making themselves sexy with Web 2.0 marketing techniques, International Journal of Technology Marketing, 2008, Vol. 3 No.2.

- Herbig, P., and Hale, B., Internet: the marketing challenge of the twentieth century, Internet Research: Electronic Networking Applications and Policy, 1997, Vol. 7, No.2, pp.95-100.

- Kaplan, A. and Haenlein, M., Users of the world, unite! The challenges and opportunities of social media, Business Horizons, 2010, vol.53, no.1.

- Keller, K. L. (2009). Building strong brands in a modern marketing communications environment. Journal of marketing communications, 15(2-3), 139-155.

- Leung, L., \& Lee, P. S. (2005). Multiple determinants of life quality: The roles of Internet activities, use of new media, social support, and leisure activities. Telematics and Informatics, 22(3), 161-180.

- Neergaard, H., Shaw, E., and Carter, S., The impact of gender, social capital and networks 
The Impact of Social Networks on Maximizing the Competitive Value of Micro, Small, and Medium Enterprises

on business ownership: a research agenda, International Journal of Entrepreneurial Behavior \& Research, 2005, Vol. 11, No.5, pp.338-57.

- Pan, J., Vorvoreanu, M., and Zhou, Zh., Social media adoption in disaster restoration industry, Construction Innovation: Information, Process, Management, 2014, Volume: 14, Issue: 3.

- Raacke, J., \& Bonds-Raacke, J. (2008). MySpace and Facebook: Applying the uses and gratifications theory to exploring friend-networking sites. Cyberpsychology \& behavior, 11(2), 169-174.

- Reese, M., and Hopkins, P., Towards the integration of social media with traditional information systems, International Conference on Computer Mediated Social Networking, 2009, pp.119-133.

- Ridings, C.M., and Gefen, D., Virtual community attraction: why people hang out online, Journal of Computer-Mediated Communication, 2004, Vol. 10 No.1.

- Sparrowe, R. T., Liden, R. C., Wayne, S. J., \& Kraimer, M. L. (2001). Social networks and the performance of individuals and groups. Academy of management journal, 44(2), 316-325.

- Tetan, D., and Allen, S., Virtual Handshake: Opening Doors and Closing Deals Online, Amacom, New York, NY, 2005.

- Tolsdorf, C. C. (1976). Social networks, support, and coping: An exploratory study. Family process, 15(4), 407-417.

- Uhrig, J., Bann, C., Williams, P., and Evans, W., Social networking websites as a platform for disseminating social marketing interventions: an exploratory pilot study, Social Marketing Quarterly, 2010, Vol. XVI, No.1, pp.1-19.

- Vij, D., \& James, D. L. (2014). A Study On Changing Trends In Social Media And Its Impact Globally. International Journal of Entrepreneurship \& Business Environment Perspectives, 3(1), 848-853.

- Wellman, B., and Gulia, M., Net-surfers do not ride alone: virtual communities as communities, in Wellman, B. (Eds), Networks in the Global Village: Life in Contemporary Communities, Westview, Boulder, 1999, pp.331-366.

- Wilson, N.C., and Stokes, D., Laments and serenades: relationship marketing and legitimation strategies for the cultural entrepreneur, Qualitative Market Research: An International Journal, 2004, Vol. 7 No.3.

- Witt, P., Entrepreneurs networks and the success of start-ups, Entrepreneurship and Regional Development, 2004, pp.391-412.

- Yoon, E., and Zhou, W., Mixed strategy multiple-channel retailing with RFID information, Journal of Organizational Computing and Electronic Commerce, 2011, Vol. 21, No.4, pp.368-83. 